\title{
Community knowledge, attitudes and practices towards Malaria in Ha- Lambani, Limpopo Province, South Africa: A cross-sectional household survey
}

Mukhethwa Munzhedzi ( $\square$ holymunzhedzi@gmail.com )

University of Venda https://orcid.org/0000-0003-1082-0881

Elizabeth T. Rogawski McQuade

University of Virginia

Jennifer L. Guler

University of Virginia

Piper E. Shifflett

University of Virginia

Sara Krivacsy

University of Virginia

Rebecca Dillingham

University of Virginia

Pascal O. Bessong

University of Venda

Research

Keywords: Plasmodium malaria, Knowledge, attitudes and Practices, Ha-Lambani, Limpopo Province, South Africa

Posted Date: December 15th, 2020

DOI: https://doi.org/10.21203/rs.3.rs-126229/v1

License: (c) (i) This work is licensed under a Creative Commons Attribution 4.0 International License. Read Full License

Version of Record: A version of this preprint was published at Malaria Journal on April 17th, 2021. See the published version at https://doi.org/10.1186/s12936-021-03724-z. 


\section{Abstract \\ Background}

Malaria remains a global health concern and is endemic in Limpopo, Mpumalanga and KwaZulu Natal Provinces of South Africa, which aims to eliminate malaria by 2025. Community engagement plays a significant role in improving the acceptability and effectiveness of programmes aimed at reducing malaria transmission. The success of such intervention efforts depends on the knowledge, attitudes and practices (KAP) of the community, and understanding the KAP of community residents may support malaria control efforts in the locality. In this context, we conducted a cross-sectional household survey to assess community KAP on malaria transmission and prevention in the Ha-Lambani village, Vhembe District, Limpopo Province.

\section{Methods}

Data were collected between November 2018 and May 2019 by questionnaire of 261 consenting adults ( 213 females and 48 males, ages between $18-$ 95 years) selected from different households. We also conducted a focus group discussion among 13 randomly selected participants. Chi Square tests were used to determine statistical differences by village.

\section{Results}

Study participants $(100 \%, 261 / 261)$ were aware of the presence of malaria in their community and $95 \%$ associated it with mosquito bites. The local health clinic was the most prominent source of malaria information (85\%). Only $22 \%$ correctly identified headache, chills and fever as the three most common symptoms of malaria. The majority of participants ( $98 \%) \mathrm{knew}$ that effective medication for malaria is available and had a positive treatment seeking behavior. Knowledge of malaria prevention measures was high (82\%); contrarily, $97 \%$ of respondents did not sleep under a bednet the previous night. The focus group data concurred with these results and also revealed that poor bednet use resulted from lack of access to bednets because community residents could not afford them.

\section{Conclusions}

The study demonstrates that participants have appropriate knowledge about malaria transmission and a positive treatment seeking behavior. However, economic barriers are responsible for the inadequate use of bednets. Therefore, distribution of bednets to the community should be considered to improve practice of malaria prevention measures. Furthermore, knowledge of signs and symptoms and appropriate malaria treatment was limited, and initiatives to improve awareness on these topics should be continued.

\section{Background}

Malaria incidence in South Africa has been estimated at 20 cases per 100000 population in 2015. In 2017, there were 22517 cases and 301 deaths. Of these cases, 8700 were from imported malaria due to cross border movements. However, in 2018, the numbers have been reduced to 9540 cases, 5742 imported cases and 69 deaths ${ }^{1}$. Amongst the known species, Plasmodium falciparum is the predominant species associated with severe and fatal disease and remains the causative agent of up to $90 \%$ of malaria cases in South Africa ${ }^{2,3}$. Malaria is restricted to the low altitude areas of three northeastern provinces, namely Limpopo, Mpumalanga and KwaZulu-Natal Provinces, where it is endemic. These provinces lie along the border with Mozambique and Zimbabwe, which experience seasonal transmission of malaria $4,5,6,7,8$. The entire Limpopo Province was historically at risk for malaria; however, through vector control by indoor residual spraying (IRS) introduced in the 1940s, malaria is now restricted to the eastern and northern areas of Mopani and Vhembe districts of the Province ${ }^{6,9}$. Thus, due to conducive environmental conditions as well as cross border movements, only certain provinces of South Africa experience seasonal malaria transmission occurring during the summer months, September to May.

Between 2015 and 2018, a dramatic increase in malaria cases was observed in Limpopo province, with a more than 10-fold increase across the summer transmission seasons (September-May). In March 2017, the Ministry of Health reported a total of 4,092 cases of malaria for the Vhembe and Mopani districts with 33 deaths. Furthermore, malaria cases were reported in non-malaria endemic provinces like Gauteng (Doornpoort) and Northwest (Swartruggens) ${ }^{10}$. Case numbers collected from the primary health clinic in Ha-Lambani in Limpopo Province increased from 6 to 190 cases during the malaria seasons of 20152018. To the best of our knowledge, no studies on malaria knowledge, attitudes and practices (KAP) have been done in this area.

Community knowledge is assessed in order to determine the level of overlap with biomedical concepts. It plays a significant role in improving the acceptability and effectiveness of programmes aimed at reducing malaria transmission. Understanding KAP of residents of a community regarding malaria can assist in the reformulation of control strategies and form the basis of appropriate health education messages as well as obtain and maintain the community's participation in surveillance and control activities $11,12,13,14,15$. Failure to consider beliefs and perceptions of the planned programmes may lead to negative attitudes or practices and contribute to failure to achieve the intended goal ${ }^{15,16}$.

In the context of sporadic high transmission of malaria with recent increases in burden in Ha-Lambani, it is important to understand the KAP of the residents of the community to gather data that may support local malaria control efforts. In this context, we conducted a cross-sectional household survey to assess community KAP surrounding malaria transmission and prevention in Ha-Lambani, Vhembe District, Limpopo Province. We observed that the Ha-Lambani community has appropriate knowledge about malaria transmission and a positive treatment seeking behavior. However, residents had poor use of bednets 
and lacked sufficient knowledge of common malaria symptoms. These data suggest that improving access to bednets and increasing malaria awareness in the Ha-Lambani community could contribute to South Africa's national malaria goals for elimination.

\section{Methods}

\section{Study design and setting}

A descriptive, cross-sectional household survey was conducted in Ha-Lambani community in the Vhembe district from November 2018 to May 2019 . HaLambani $\left(22.7108^{\circ} \mathrm{S}, 30.8442^{\circ} \mathrm{E}\right)$, is a malaria-endemic area, at a low altitude of $605 \mathrm{~m}$ above sea level. FIGURE 1 shows the spatial map of Ha-Lambani area.

Briefly, Ha-Lambani area is made up of 20 villages. It is a community of low-socioeconomic status, with a population of 15,078 people in 3015 households. The majority of residents are subsistence farmers, casual workers and pensioners. It is approximately $16 \mathrm{~km}$ away from the Kruger National Park (one of Africa's largest game reserves), an area considered low-to-medium risk for malaria transmission during summer months. Also, it is approximately $98 \mathrm{~km}$ away from Pafuri Rest Camp in Mozambique, and $176 \mathrm{~km}$ from the Zimbabwean Beit Bridge border post. The study area used for the KAP assessment comprised three villages, Masetoni, Tshihothi and Tshamulavhu, which had recently experienced significant increases in malaria cases based on statistics from the local health centre.

\section{Sampling strategy}

In the current study, 261 participants consented to participate and each was administered a free malaria rapid diagnostic test (RDT). Consent was sought from the household head then from any adult available and willing to participate. The three villages had 584 households with a total population of 2995 in 2018. For each household, only one consenting adult ( $\geq 18$ years old) was selected for interview.

\section{Data collection}

Two female homebased care workers from the local clinic were recruited and trained to support the recruitment of study participants and conduct the interviews. Trained field workers administered a questionnaire that was both in English as well as in Tshivenda (the local spoken language) to respondents that were 18 years and older. The survey questionnaire was open ended and had these sections: demographics of respondent; treatment seeking behavior; and knowledge, attitude and practices related to malaria transmission and disease. The survey questionnaire was piloted before use to ensure comprehensibility, clarity and appropriateness. After each interview, an informational pamphlet on causes of malaria, transmission, prevention and treatment, written in English or Tshivenda, was given to the household. This pamphlet was developed by collating information on malaria transmission from Tshaulu Malaria office, Thohoyandou Health Centre and Malaria Control Programme office in Thohoyandou, Limpopo Province. The pamphlet was approved by the Limpopo Provincial Department of Health. Pamphlets were also provided to outpatients of the local clinic and to the community at the end of the study, to create awareness in the community at large.

A questionnaire and a focus group discussion (FGD) were chosen as the data collection methods to ensure comprehensive methods of data collection. The questions on the interview guides were checked by other investigators not associated with the current study who have relevant knowledge and expertise to ensure that questions were correctly phrased and that they captured all the necessary information needed for the study.

\section{Focus group discussion}

After individual interviews were performed, a respondent moderator focus group discussion was conducted once wherein the researcher recruited a participant in the group to take the role of a moderator. The purpose of the focus group discussion was to obtain more information in order to confirm what was already observed from the individual questionnaires as well as to see if other themes or ideas emerged. This discussion comprised 13 randomly selected individuals: 12 individuals from the study site who were already participants (one of which served as the moderator) and 1 person who was an investigator of the current study (who served as an assistant moderator). The role of the moderator was to facilitate the discussion, ensure smooth flow of the discussion and participation by all; as well as ensuring that participants did not deviate from the topic under discussion ${ }^{17}$. The assistant moderator served as a scribe to record the participants' responses once there was a consensus as well as to tape record the participants responses in order to confirm or compare with what was written.

\section{Quality assurance and data analysis}

Quality of the data was assured by double checking the entries on Microsoft Excel version 2010. Statistical analysis was done using Social Science Statistics. Qualitative data was analyzed using descriptive statistics. Frequency distributions and percentages of variables were used to describe the sample population, quantify knowledge of malaria, attitudes and practices associated with malaria transmission and prevention. Narratives from FGD qualitative data were coded and managed using a framework of themes that addresses key issues as per study objectives. Coding and coding consistency checking was carried out. A list of codes was developed, reviewed and grouped into themes and categories for analysis. The following main themes formed the focus of the findings:

demographics of respondent; malaria knowledge (symptoms, treatment, prevention), attitude and practices; treatment seeking behavior and awareness related to malaria transmission and disease. Chi square tests were used to determine the statistical significance of difference of relative frequencies between villages, and differences by gender, age, educational level and total household income. Values were considered statistically significant when $p<0.05$.

\section{Operational definition of selected variables}

- Married: One was considered married either lawfully, traditionally or by living with husband or wife. 
- Home-based care worker: Provide routine personal care and assistance with activities of daily living to persons who are in need of such care due to effects of ageing, illness, injury, other physical or mental condition in private homes and other independent residential settings. They are usually members of the local community, give health talks to their patients and their families as well as cooperate with the advice and support from the trained health workers from the local health clinic.

- Field worker: Someone who is trained to work outside of the office and travel to different locations to recruit study participants (administering questionnaires and conducting interviews for data collection).

- Musuzungwane: Scientifically known as Lippia javanica, is a plant that is traditionally used to ward off mosquitos by its smell.

- Bunganyunyu plant: A plant that is traditionally used toward off mosquitos by its smell.

- Mudinyane: Another alternative name for malaria that used by some of the current study participants.

\section{Ethical consideration}

The study protocol was approved by the Research Ethics and Clinical Trial Committee of the University of Venda (protocol number: SMNS/18/MBY/09/0507). Permission to use local health facility was obtained from the Limpopo Provincial Department of Health (Ref: LP_2018 08-020). Also, permission to conduct the study in the community was obtained from the community leader of Ha-Lambani area. Informed consent was obtained from each study participant before proceeding with the survey. Anonymity of study participants was adhered to.

\section{Results}

\section{Demographic characteristics of the study population}

A total of 261 questionnaires were completed, with no refusals, and $100 \%$ of the questions were answered. Females accounted for approximately $82 \%$ $(213 / 261)$ of the total study population. The ages of the participants ranged from 18 to 95 years, with a mean, median and standard deviation of $44.1,40$ and \pm 18.1 respectively. Most of the study participants were mothers $(70.1 \%, 183 / 261)$. The majority of respondents, $71.6 \%(187 / 261)$ were unemployed (casual workers and pensioners) and more than three quarters of them $79.3 \%(207 / 261)$ had at least primary school level education. In addition, $1.9 \%$ (5/261) of the participants reported that they had malaria (tested by Rapid Diagnostic tests) within the previous 3 months. One focus group discussion was conducted after the individual interviews and constituted of men and women aged between 21 and 79 years old. Table 1 (See additional file 1) represents the demographics of the study participants. 
Table 1

Demographic characteristics of study participants by village

\begin{tabular}{|c|c|c|c|c|}
\hline Village name & $\begin{array}{l}\text { Masetoni } \\
n=86\end{array}$ & $\begin{array}{l}\text { Tshihothi } \\
\mathrm{n}=\mathbf{4 1}\end{array}$ & $\begin{array}{l}\text { Tshamulavhu } \\
n=134\end{array}$ & $\begin{array}{l}\text { Total } \\
\mathbf{n}=\mathbf{2 6 1}\end{array}$ \\
\hline Gender & $\mathrm{n}(\%)$ & $\mathrm{n}(\%)$ & $\mathrm{n}(\%)$ & $\mathrm{n}(\%)$ \\
\hline Male & 18(20.9) & $7(17.1)$ & $23(17.2)$ & $48(18.4)$ \\
\hline Female & $68(79.1)$ & $34(82.9)$ & $111(82.8)$ & 213(81.6) \\
\hline \multicolumn{5}{|l|}{ Age (range 18-95) } \\
\hline$\leq 30$ & $31(36)$ & $6(14.6)$ & $32(23.9)$ & $69(26.4)$ \\
\hline $31-50$ & $27(31.4)$ & $17(41.5)$ & 59 (44.) & 103 (39.5) \\
\hline$>50$ & $28(32.6)$ & $18(43.9)$ & $43(32.1)$ & 8) 34.1) \\
\hline Mean & & & & 44.1 \\
\hline Median & & & & 40 \\
\hline Mode & & & & 29 \\
\hline SD & & & & 18.1 \\
\hline \multicolumn{5}{|l|}{ Marital Status } \\
\hline Never Married & $86(100)$ & $12(29.3)$ & $45(33.6)$ & $144(55.2)$ \\
\hline Married & $0(0)$ & $27(65.9)$ & $80(59.7)$ & $107(41.0)$ \\
\hline Divorced & $0(0)$ & $1(2.4)$ & $3(2.2)$ & $4(1.5)$ \\
\hline Widowed & $0(0)$ & $1(2.4)$ & $5(3.7)$ & $6(2.3)$ \\
\hline \multicolumn{5}{|l|}{ Nationality } \\
\hline South African & $86(100)$ & $41(100)$ & 134(100) & $261(100)$ \\
\hline \multicolumn{5}{|l|}{ Ethnicity } \\
\hline Vha-Venda & 85(98.8) & $41(100)$ & 134(100) & 261(99.6) \\
\hline Va-Tsonga & $1(1.2)$ & $0(0)$ & $0(0)$ & $1(0.4)$ \\
\hline \multicolumn{5}{|l|}{ Language } \\
\hline Tshivenda & $86(100)$ & $41(100)$ & 134(100) & 261(100) \\
\hline \multicolumn{5}{|l|}{ Religion } \\
\hline Christian & 77 (89.5) & $37(90.2)$ & $129(96.3)$ & 243(93.1) \\
\hline Traditional & $7(8.1)$ & $4(9.8)$ & $3(2.2)$ & $14(5.4)$ \\
\hline Other ${ }^{\mathrm{a}}$ & $2(2.3)$ & $0(0)$ & $2(1.5)$ & $4(1.5)$ \\
\hline \multicolumn{5}{|l|}{ Family Position } \\
\hline Father & 19(22) & $8(19.5)$ & 17(12.6) & $44(16.8)$ \\
\hline Mother & $56(65)$ & $24(58.5)$ & 103(76.3) & $183(69.8)$ \\
\hline Legal guardian & $1(1)$ & $0(0)$ & $0(0)$ & $1(0.4)$ \\
\hline Young adult & $10(12)$ & $9(22)$ & 15(11.1) & $34(13.0)$ \\
\hline \multicolumn{5}{|l|}{ Level of education } \\
\hline No formal education & $20(23)$ & $9(22)$ & 25(18.7) & $54(20.7)$ \\
\hline Primary level & $22(26)$ & 15(36.6) & $30(22.4)$ & $67(25.7)$ \\
\hline Secondary level & $41(48)$ & $16(39)$ & $75(56)$ & $132(50.6)$ \\
\hline Tertiary level & $3(3)$ & $1(2.4)$ & $4(3)$ & $8(3.1)$ \\
\hline \multicolumn{5}{|l|}{ Occupation } \\
\hline Unemployed & $62(72.1)$ & $27(65.9)$ & 98(73.1) & 187(71.6) \\
\hline
\end{tabular}

Other ${ }^{\mathrm{a}}$ represents neither, traditional or Christian. Other ${ }^{\mathrm{b}}$ included government grant dependent and pensioner. 


\begin{tabular}{|c|c|c|c|c|}
\hline Village name & $\begin{array}{l}\text { Masetoni } \\
\mathrm{n}=86\end{array}$ & $\begin{array}{l}\text { Tshihothi } \\
\mathrm{n}=\mathbf{4 1}\end{array}$ & $\begin{array}{l}\text { Tshamulavhu } \\
n=134\end{array}$ & $\begin{array}{l}\text { Total } \\
\mathbf{n}=\mathbf{2 6 1}\end{array}$ \\
\hline Employed & $8(9.3)$ & $2(4.9)$ & $5(3.7)$ & $15(5.7)$ \\
\hline Government grant dependent & 16(18.6) & $11(26.8)$ & $31(23.1)$ & $58(22.2)$ \\
\hline Other ${ }^{b}$ & $0(0)$ & $1(2.4)$ & $0(0)$ & $1(0.40$ \\
\hline \multicolumn{5}{|l|}{ Total household income } \\
\hline$<3000$ & $80(93.0)$ & $40(97.6)$ & $130(97.0)$ & $250(95.8)$ \\
\hline $3000-10000$ & $5(5.8)$ & $1(2.4)$ & $2(1.5)$ & $8(3.1)$ \\
\hline$<10000$ & $1(1.2)$ & $0(0)$ & $2(1.50$ & $3(1.1)$ \\
\hline \multicolumn{5}{|l|}{ Malaria history: Past 3 months } \\
\hline Yes & $1(1.2)$ & $2(4.9)$ & $2(1.5)$ & $5(1.9)$ \\
\hline No & $85(98.8)$ & $39(95.1)$ & 132(98.5) & 256(98.1) \\
\hline \multicolumn{5}{|l|}{ Past 5 years } \\
\hline Yes & $56(65.1)$ & $31(75.6)$ & $58(43.0)$ & $145(55.6)$ \\
\hline No & $30(34.9)$ & $10(24.4)$ & $77(57.0)$ & $116(44.4)$ \\
\hline \multicolumn{5}{|l|}{ Fever History: Past 3 days } \\
\hline Yes & $4(4.7)$ & $1(2.4)$ & $5(3.7)$ & $10(3.8)$ \\
\hline No & $82(95.3)$ & $40(97.6)$ & $129(96.3)$ & $251(96.2)$ \\
\hline
\end{tabular}

\section{Malaria knowledge}

Participants' knowledge on the transmission of malaria.

Of the 261 participants, all $(100 \% ; 261)$ had heard about malaria, with about $95 \%(247 / 261)$ correctly associating malaria with mosquito bites. However, a small number of the participants had no knowledge about malaria transmission at all and this proportion differed significantly across the villages; Masetoni (5.8\%), Tshamulavhu (1.5\%), Tshihothi (12.2\%) ( $P=0.01)$. When asked about their general view of malaria, the majority of study participants (93.1\%; $243 / 261)$ who had heard about malaria further demonstrated appropriate knowledge of malaria by recognizing it as a problem, stating that it is dangerous, that it can kill if not treated early, it's a terrible or frightening illness; or by directly stating that it is a problem. However, only $1.9 \%(5 / 261)$ and $3.1 \%(8 / 261)$ of the study participants mentioned malaria signs and symptoms; and prevention methods, respectively. Although majority of study participants recognize malaria as a health problem in the community, only $2 \%$ (5/261) recognized the proximity of Kruger National Park to the study area as an important risk factor for the transmission of malaria. Of note, $97 \%$ (253/261) of participants who believe that malaria is dangerous and kills or see it as a health problem have been resident in the study area for at least 5 years. TABLE 2 (See additional file 2) shows the details on the knowledge and perception on malaria transmission of study participants.

TABLE 2: Reported knowledge and perception on malaria transmission; and its occurrence in Ha-Lambani area by village 


\begin{tabular}{|c|c|c|c|c|c|}
\hline Village name & $\begin{array}{l}\text { Masetoni } \\
\mathrm{n}=86\end{array}$ & Tshihothi $n=41$ & $\begin{array}{l}\text { Tshamulavhu } \\
\mathrm{n}=134\end{array}$ & Total $n=261$ & $p$ value \\
\hline 1.1 Have you heard of malaria? & $\mathrm{n}(\%)$ & $\mathrm{n}(\%)$ & $\mathrm{n}(\%)$ & $\mathrm{n}(\%)$ & $(a=0.05)$ \\
\hline Yes & $86(100)$ & $41(100)$ & $134(100)$ & $261(100)$ & - \\
\hline No & $0(0)$ & $0(0)$ & $0(0)$ & $0(0)$ & - \\
\hline \multicolumn{6}{|l|}{ 1.2. Knowledge of malaria transmission } \\
\hline Mosquito bites & $80(93)$ & $36(87.8)$ & 131(97.8) & $247(94.6)$ & $P=0.03$ \\
\hline Don't know & $5(5.8)$ & $5(12.2)$ & $2(1.5)$ & $12(4.6)$ & $P=0.01$ \\
\hline Other transmission ${ }^{c}$ & $1(1.2)$ & $0(0)$ & $1(0$ & $2(0.80$ & - \\
\hline \multicolumn{6}{|l|}{ 1.3. What is your general view of malaria? } \\
\hline It kills, dangerous, a lot or problematic & $80(93)$ & $39(95.1)$ & $124(92.5)$ & 243(93.1) & $P=0.84$ \\
\hline Mentions malaria symptom(s) & $1(1.2)$ & $0(0)$ & $4(3)$ & $5(1.9)$ & - \\
\hline Mentions prevention method(s) & $2(2.3)$ & $1(2.4)$ & $5(3.7)$ & $8(3.1)$ & $P=0.82$ \\
\hline No comment & $3(3.5)$ & $1(2.4)$ & $1(0.7)$ & $5(1.9)$ & $P=0.34$ \\
\hline \multicolumn{6}{|c|}{ 1.4. What can you say about its occurrence in the Ha-Lambani area in years } \\
\hline It kills, dangerous, a lot or problematic & $75(87.2)$ & $40(97.6)$ & 131(97.8) & $246(94.30$ & $P=0.00$ \\
\hline Mentions malaria symptom(s) & $3(3.5)$ & $0(0)$ & $0(0)$ & $3(1.1)$ & - \\
\hline Mentions prevention method(s) & $7(8.1)$ & $0(0)$ & $3(2.2)$ & 10(3.8) & - \\
\hline Others $^{d}$ & $1(1.2)$ & $1(2.4)$ & $0(0)$ & $2(0.80$ & - \\
\hline \multicolumn{6}{|c|}{ 1.5. Length of stay in Ha-Lambani area in years } \\
\hline$\leq 4$ & $3(3.5)$ & $1(2.4)$ & $4(3)$ & $8(3.1)$ & $P=0.95$ \\
\hline$\geq 5$ & $83(96.5)$ & $40(97.6)$ & 130(97.) & 253(96.9) & $P=0.95$ \\
\hline \multicolumn{6}{|c|}{ 1.6 Relating malaria to Kruger National Park } \\
\hline Yes & $3(3.5)$ & $0(0)$ & $2(1.5)$ & $5(1.9)$ & - \\
\hline No & $83(96.50$ & $41(100)$ & 132(98.5) & $256(98.1)$ & - \\
\hline Total & $86(100)$ & $41(100)$ & $134(100)$ & 261 & \\
\hline
\end{tabular}

Other ${ }^{\mathbf{c}}$ transmission routes included drinking bad water and other ${ }^{\mathbf{d}}$ perceptions of malaria in the Ha-Lambani village specifically included refusing to use the same alcohol cup as a person with malaria and no comment. Chi-square test for differences in prevalence across villages.

The study participants gave a wide range of sources of malaria information (Table 3). However, clinics (health centers) (84.7\%; 221/261) were the most prominent sources. Family was also an information source in some villages, but not others $(P=0.03)$, while other sources were not commonly reported in any of the villages (Indoor residual Spraying (IRS) team, television, home-based care workers, neighbors or newspapers, $\mathrm{P}=0.85$ ). Additionally, friends were the least common source of malaria information $(1.1 \% ; 3 / 261)$.

Table 3

Reported sources of malaria information by village

\begin{tabular}{|llllll|}
\hline Village name & Masetoni $\mathrm{n}=\mathbf{8 6}$ & Tshihothi $\mathrm{n}=\mathbf{4 1}$ & $\begin{array}{c}\text { Tshamulavhu } \\
\mathrm{n}=134\end{array}$ & $\begin{array}{l}\text { Total } \\
\mathrm{n}=\mathbf{2 6 1}\end{array}$ & $\mathrm{p}$ value \\
\hline Source of malaria knowledge & $\mathrm{n}(\%)$ & $\mathrm{n}(\%)$ & $\mathrm{n}(\%)$ & $\mathrm{n}(\%)$ & $\mathrm{a}=\mathbf{0 . 0 5}$ \\
\hline Radio & $0(0)$ & $3(7.3)$ & $3(2.2)$ & $6(2.3)$ & - \\
\hline School & $3(3.5)$ & $0(0)$ & $3(2.2)$ & $6(2.30$ & - \\
\hline Clinic & $78(90.7)$ & $32(78.0)$ & $111(82.8)$ & $221(84.7)$ & $\mathrm{P}=0.13$ \\
\hline Friends & $1(1.2)$ & $0(0)$ & $2(1.5)$ & $3(1.10$ & - \\
\hline Family & $1(1.2)$ & $5(12.2)$ & $12(9)$ & $18(6.9)$ & $\mathrm{P}=0.03$ \\
\hline Other sources & $\mathrm{e}$ & $1(2.4)$ & $3(2.20$ & $7(2.7)$ & $\mathrm{P}=0.85$ \\
\hline Total & $3(3.5)$ & $\mathbf{4 1 ( 1 0 0 )}$ & $\mathbf{1 3 4 ( 1 0 0 )}$ & $\mathbf{2 6 1 ( 1 0 0 )}$ & - \\
\hline
\end{tabular}


Other sources ${ }^{\mathbf{e}}$ of malaria information included Indoor residual Spraying team, television, home-based care workers, neighbors or newspaper. Chi-square test for differences in prevalence across villages.

Participants knowledge on malaria symptoms and treatment.

Malaria signs and symptoms such as headache, vomiting and diarrhea were the most frequently reported. However, participants also mentioned sweating, loss of appetite, fever and chills; and to a lesser extent fatigue, loss of weight, joint pains and others. One participant $(0.4 \%, 1 / 261)$ did not know of any symptoms of malaria (FIGURE 2). Overall, about 99.2\% (259/261) correctly identified at least one of the three most common symptoms of malaria (headache, chills and fever $\left.{ }^{1}\right)$. However, only $21 \%(56 / 261)$ of the participants were able to correctly identify all 3 of these most common symptoms of malaria.

\subsubsection{Participants knowledge on malaria treatment}

The participants' knowledge of malaria treatment was low, with only one participant mentioning quinine as a drug to treat malaria. However, a majority of the participants knew that effective treatments for malaria are available (98.08\%; 256/261) and 83.5\% (218/261) mentioned tablets/pills as medication for malaria treatment. Only $1.5 \%(4 / 261)$ of the respondents had no knowledge of any form of malaria treatment (TABLE 4).

TABLE 4: Reported knowledge of malaria treatment of participants by village

\begin{tabular}{|lllll|}
\hline Village name & Masetoni $\mathbf{n = 8 6}$ & Tshihothi $\mathbf{n = 4 1}$ & Tshamulavhu $\mathbf{n = 1 3 4}$ & $\begin{array}{c}\text { Total } \\
\mathbf{n = 2 6 1}\end{array}$ \\
\hline What do you know about malaria treatment? & $\mathbf{n}(\%)$ & $\mathrm{n}(\%)$ & $\mathrm{n}(\%)$ & $\mathbf{n}(\%)$ \\
\hline Pills & $77(89.5)$ & $31(75.6)$ & $110(88.8)$ & $218(83.5)$. \\
\hline Quinine & $0(0)$ & $0(0)$ & $1(0.74)$ & $1(0.74)$ \\
\hline Clinic & $7(8.1)$ & $3(7.3)$ & $4(3)$ & $14(5.4)$ \\
\hline Drip (intravenous) & $0(0)$ & $1(2.4)$ & $1(0.7)$ & $2(0.8)$ \\
\hline Pills and/ medicine & $1(1.2)$ & $2(4.9)$ & $3(2.2)$ & $6(2.3)$ \\
\hline Pills and drips & $1(1.2$ & $0(0)$ & $2(1.5)$ & $3(1.1)$ \\
\hline pills, drips(intravenous) & $0(0)$ & $2(4.9)$ & $3(2.2)$ & $5(1.9)$ \\
\hline Hospital & $0(0)$ & $1(2.4)$ & $0(0)$ & $1(0.4)$ \\
\hline Other & $6(7)$ & $0(0)$ & $1(0.7)$ & $7(2.7)$ \\
\hline None & $2(2.3)$ & $1(2.4)$ & $1(0.7)$ & $4(1.5)$ \\
\hline Total & $86(100)$ & $41(100)$ & $134(100)$ & $261(100)$ \\
\hline
\end{tabular}

Other ${ }^{f}$ reported treatment options included mentioning that it works, those with malaria should adhere to it and that it is helpful.

Attitudes and practices towards Malaria.

Treatment seeking behavior of participants.

A total of $97.7 \%(255 / 261)$ of the participants had a positive attitude regarding seeking treatment by stating that they would take their child to clinic if they had symptoms such as fever. However, a small proportion $(3 \% ; 3 / 261)$ reported that they would either use Panado (paracetamol), pray or talk to their pastor (Table 5).

Table 5

Reported treatment seeking behavior of participants by Village

\begin{tabular}{|c|c|c|c|c|}
\hline \multirow[t]{2}{*}{$\begin{array}{l}\text { Treatment seeking behavior (when seeking child care e.g. when a child has } \\
\text { fever) }\end{array}$} & $\begin{array}{l}\text { Masetoni } n= \\
86\end{array}$ & $\begin{array}{l}\text { Tshihothi } n= \\
41\end{array}$ & $\begin{array}{l}\text { Tshamulavhu } \mathrm{n}= \\
134\end{array}$ & $\begin{array}{l}\text { Total } n= \\
261\end{array}$ \\
\hline & $\mathrm{n}(\%)$ & $\mathrm{n}(\%)$ & $\mathrm{n}(\%)$ & $\mathrm{n}(\%)$ \\
\hline Consult at the clinic & $84(97.7)$ & $41(100)$ & 130(97) & 255(97.7) \\
\hline Give him Panado & $0(0)$ & $0(0)$ & $1(0.7)$ & $1(0.4)$ \\
\hline Praying, talk to the pastor then clinic & $0(0)$ & $0(0)$ & $2(1.5)$ & $2(0.8)$ \\
\hline Others $\mathrm{g}$ & $2(2.3)$ & $0(0)$ & $1(0.7)$ & $3(1.1)$ \\
\hline
\end{tabular}

Other ${ }^{g}$ steps to take when seeking childcare included calling the ambulance, giving the child boiled lemon leaves to drink and breastfeeding the child more.

Participants knowledge and practices on malaria prevention. 
Most of the study participants were aware of malaria prevention measures $(81.9 \% ; 214 / 261)$. However, the rest of the study participants either did not know or mentioned an incorrect malaria prevention measure(s) such as using clean water, eating clean food and drinking soft drink. Amongst other prevention measures, wearing long-sleeved clothes $(39.1 \%, 102 / 261)$ proved to be the most prominent in the study population; this was followed by using bednets $(23.8 \%, 62 / 261)$ and these proportions differed across villages (Masetoni (48.8\%), Tshamulavhu (44\%), Tshihothi $(2.4 \% ; p=0.00) ;$ Masetoni $(27.9 \%)$, Tshamulavhu (26.1\%), Tshihothi $(7.3 \%, p=0.03)$ respectively.

Also, most $(85.4 \%$; 223/261) of the study participants correctly reported removal of stagnant water and removal of used cow dung (for decorations), proper disposal of empty cans or keeping their compound clean as ways to prevent mosquito breeding. Many of these proportions differed significantly across villages ( $p=0.00, p=0.00, p=0.00, p=0.23$, respectively) (TABLE 6: See additional file 3). Removal of stagnant water or covering water bodies was the most frequently reported measure to prevent mosquito breeding $(47.9 \% ; 125 / 261)$, however, some participants either did not know or mentioned incorrect mosquito breeding prevention measures. A high proportion of participants $(98 \% ; 256 / 261)$ reported that they adhere to the above-mentioned malaria prevention measures while the rest of the participants $(2 \%, 5 / 261)$ either did so sometimes or did not adhere to any measure at all. Of note, $96.9 \%(253 / 261)$ of the study participants reported not to have slept under a bednet the previous night.

Participants' reasons for participating in the study.

The study participants had different reasons for participating in the current study (FIGURE 3). Majority of the participants reported the need to know their health status followed by recognizing malaria studies as important or helpful to the community as reasons for participating. Also, the rest of the participants mentioned reasons such as malaria is a problem, they have suffered from malaria or to be more informed about malaria. To a lesser extent, participants mentioned that they will not need to travel long distances to get to the clinic to get tested for malaria

Knowledge of malaria transmission, symptoms, treatment and prevention stratified by gender, age, educational level and total household income.

Female participants had more knowledge on malaria transmission $(77.4 \%, 151 / 195)$ compared to males $27.6 \%$ (44/195). Knowledge on malaria transmission knowledge was insignificantly higher for participants with secondary school education than other levels $(p=0.51)$ and significantly comparable $(P=0.05)$ for participants who were 30 years of age and below compared to those above 30 years. Participants who had resided in the village for 5 years and more had greater knowledge of malaria transmission compared to participants who stayed less than 5 years $(p=0.06)$.

The study participants' knowledge on malaria symptoms was significantly higher for females than males $(P=0.00)$; and significantly lower for participants aged 30 and below compared to those above 30 years $(P=0.02)$. Moreover, the participants' knowledge on malaria treatment and prevention was significantly higher for females than males $(P=0.00),(P=0.00)$ respectively. Total household income was not associated with participants knowledge on malaria transmission, symptoms, treatment or prevention (TABLE 7: see additional file 4).

TABLE 6: Reported knowledge on malaria prevention and practices of participants by village. 


\begin{tabular}{|c|c|c|c|c|c|}
\hline Village name & Masetoni $n=86$ & Tshihothi $n=41$ & Tshamulavhu $n=134$ & Total $n=261$ & $\mathrm{p}$ value \\
\hline Characteristic & $n(\%)$ & $n(\%)$ & $\mathrm{n}(\%)$ & $n(\%)$ & $a=0.05$ \\
\hline \multicolumn{6}{|l|}{ 2.3. Knowledge of malaria prevention } \\
\hline Using bednets & $24(27.9)$ & $3(7.3)$ & $35(26.1)$ & $62(23.8)$ & $P=0.03$ \\
\hline Burning cow dung/ Musuzungwane plant leaves (Lippia javanica) & 10(11.6) & $5(12.2)$ & $28(20.9)$ & $43(16.5)$ & $P=0.14$ \\
\hline Removal of dirty or stagnant water & 13(15.1) & $0(0)$ & $9(6.7)$ & $22(8.4)$ & \\
\hline Removal of used cow dung & $0(0)$ & $0(0)$ & $(2.2) 3$ & $3(1.1)$ & \\
\hline Wearing long sleeved clothes & $42(48.8)$ & $1(2.4)$ & $59(44)$ & 102(39.1) & $P=0.00$ \\
\hline using mosquito repellants & $5(5.8)$ & $3(7.3)$ & $5(3.7)$ & 13(5) & $P=0.59$ \\
\hline Using mosquito coils & $5(5.8)$ & $1(2.4)$ & 12(9) & $18(6.9)$ & $P=0.32$ \\
\hline Burying empty cans & $7(8.1)$ & $1(2.4)$ & $5(3.7)$ & $13(5)$ & $P=0.24$ \\
\hline Keeping cleanliness & 10(11.6) & $1(2.4)$ & $13(9.7)$ & $24(9.2)$ & $P=0.23$ \\
\hline Allow IRS workers to spray your house & $8(9.3)$ & $3(7.3)$ & $8(6)$ & $19(7.3)$ & $P=0.27$ \\
\hline Closing windows & $8(9.3)$ & $4(9.8)$ & $4(3)$ & $16(6.1)$ & $P=0.09$ \\
\hline Clinic/ treatment & $1(1.2)$ & $2(4.9)$ & $3(2.2)$ & $6(2.3)$ & $P=0.42$ \\
\hline Don't know & $0(0)$ & $3(7.3)$ & $1(0.7)$ & $4(1.5)$ & - \\
\hline Other ${ }^{h}$ & $1(1.2)$ & $1(2.4)$ & $6(4.5)$ & $8(3.1)$ & $P=0.37$ \\
\hline \multicolumn{6}{|l|}{ 3.1. Knowledge of preventing mosquito breeding } \\
\hline Removal of dirty, stagnant water or covering water holes & $47(54.7)$ & $1(2.4)$ & $77(57.5)$ & $125(47.9)$ & $P=0.00$ \\
\hline Removal of used cow dung & 10(11.6) & $27(65.9)$ & $25(18.7)$ & $62(23.8)$ & $P=0.00$ \\
\hline Proper tin disposal & $29(33.7)$ & $1(2.4)$ & $20(14.9)$ & $50(19.2)$ & $P=0.00$ \\
\hline Clean compound & $8(9.3)$ & $8(19.5)$ & $25(18.7)$ & $33(12.6)$ & $P=0.14$ \\
\hline Don't know & $3(3.5)$ & $1(2.4)$ & $5(3.7)$ & $9(3.4)$ & $P=0.92$ \\
\hline Incorrect measuresi & 14(16.3) & $10(24.4)$ & $5(3.7)$ & $29(11.1)$ & $P=0.00$ \\
\hline \multicolumn{6}{|l|}{ 3.2. Adherence to preventative measures } \\
\hline Yes & $85(98.8)$ & $41(100)$ & 130(97) & 256(98) & - \\
\hline No & $0(0)$ & 0 & $1(0.7)$ & $1(0)$ & - \\
\hline Sometimes & $1(1.2)$ & 0 & $3(2.2)$ & $4(2)$ & - \\
\hline \multicolumn{6}{|l|}{ 3.1. Did you sleep under a bednet last night? } \\
\hline Yes & $2(2.3)$ & 0 & $6(4.5)$ & $8(3.1)$ & - \\
\hline No & $84(97.7)$ & $41(100)$ & 128(95.5) & 253(96.9) & - \\
\hline
\end{tabular}

Percentage total exceed 100 because of multiple responses. Other ${ }^{h}$ prevention measures included the use of clean water, fans, clean food, drinking stoney soft drink to prevent malaria. Incorrect prevention measuresi included the use of bednets, closing windows, shaking off curtains, wearing long sleeved clothes, burning mosquito coils or using mosquito repellants. Chi-square test for differences in prevalence across villages.

TABLE 7: Knowledge of malaria stratified by gender, age, educational level and total household income 


\begin{tabular}{|c|c|c|c|c|c|c|c|c|c|c|c|}
\hline \multicolumn{2}{|l|}{ Characteristic } & \multirow{2}{*}{$\begin{array}{l}\begin{array}{l}\text { Total } \\
\mathbf{n}=261\end{array} \\
48(18.39)\end{array}$} & \multirow{2}{*}{$\begin{array}{l}\text { Knowledge } \\
\text { on malaria }\end{array}$} & \multirow{2}{*}{$\begin{array}{l}P \text { value } \\
P=0.76\end{array}$} & \multirow{2}{*}{$\begin{array}{l}\begin{array}{l}\text { Knowledge } \\
\text { on malaria } \\
\text { transmission }\end{array} \\
44(22.6)\end{array}$} & \multirow{2}{*}{$\begin{array}{l}P \text { value } \\
P=0.00\end{array}$} & \multirow{2}{*}{$\begin{array}{l}\text { Knowledge } \\
\text { on malaria } \\
\text { Symptoms } \\
94(36.6)\end{array}$} & \multirow{2}{*}{$\begin{array}{l}P \text { value } \\
P=0.00\end{array}$} & \multirow{2}{*}{$\begin{array}{l}\text { Knowledge } \\
\text { on malaria } \\
\text { treatment }\end{array}$} & \multirow{2}{*}{$\begin{array}{l}P \text { value } \\
P=0.00\end{array}$} & \multirow{2}{*}{ 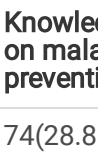 } \\
\hline Gender & Male & & & & & & & & & & \\
\hline & Female & $213(81.61)$ & 213(81.61) & $P=0.76$ & 151(77.4) & $P=0.00$ & $163(63.4)$ & $P=0.00$ & 184(71.6) & $P=0.00$ & $183(71$. \\
\hline Total & & 261 & 261 & & 195 & & 257 & & 257 & & 257 \\
\hline \multirow[t]{3}{*}{ Age } & $\leq 30$ & 69(26.4) & $69(26.44)$ & $P=0.02$ & $66(26.5)$ & $P=0.05$ & 75(29.2) & $P=0.02$ & $67(26.1)$ & $P=0.166$ & $68(26.5$ \\
\hline & $31-50$ & 103(39.5) & 103(39.46) & $P=0.38$ & $100(40.2)$ & $P=0.12$ & $95(36.96)$ & $P=0.12$ & 98(38.1) & $P=0.10$ & 102(39. \\
\hline & $>50$ & $89(34.1)$ & 89(34.1) & $P=0.35$ & 83(33.3) & $P=0.73$ & $87(33.85)$ & $P=0.53$ & 92(35.8) & $P=0.33$ & $87(33.9$ \\
\hline Total & & 261 & 261 & & 249 & & 257 & & 257 & & 257 \\
\hline \multirow[t]{4}{*}{$\begin{array}{l}\text { Educational } \\
\text { level }\end{array}$} & $\begin{array}{l}\text { No formal } \\
\text { education }\end{array}$ & $54(20.7)$ & $54(20.7)$ & $P=0.71$ & $47(18.9)$ & $P=0.37$ & $54(21.7)$ & $P=0.06$ & $53(20.62)$ & $P=0.54$ & $52(20.3$ \\
\hline & Primary & $67(25.7)$ & $67(25.7)$ & $P=0.11$ & $67(26.9)$ & $P=0.13$ & $59(23.7)$ & $P=0.13$ & $66(25.68)$ & $P=0.29$ & $64(25)$ \\
\hline & secondary & $132(50.6)$ & $132(50.6)$ & $P=0.00$ & $116(46.6)$ & $P=0.51$ & $125(50.2)$ & $P=0.09$ & $132(51.36)$ & $P=0.79$ & $130(50$. \\
\hline & Tertiary & $8(3.1)$ & $8(3.10$ & $P=0.95$ & 19(7.6) & $P=0.06$ & $11(4.4)$ & $P=0.19$ & $6(2.33)$ & $P=1.109$ & 10(3.91 \\
\hline Total & & 261 & 261 & & 249 & & 249 & & 257 & & 256 \\
\hline \multirow{3}{*}{$\begin{array}{l}\text { Total } \\
\text { household } \\
\text { income }\end{array}$} & $<3000$ & 250(95.8) & 250(95.8) & $P=0.29$ & $239(94.1)$ & $P=0.07$ & $244(94.9)$ & $P=0.21$ & $246(95.7)$ & $P=0.83$ & $248(96$. \\
\hline & $\begin{array}{l}3000- \\
10000\end{array}$ & $8(3.1)$ & $8(3.1)$ & $P=0.19$ & $12(4.7)$ & $P=0.03$ & $8(3.1)$ & $P=0.16$ & $7(2.7)$ & $P=1.10$ & 6 \\
\hline & $>10000$ & $3(1.1)$ & $3(1.1)$ & - & $3(1.2)$ & - & $5(1.9)$ & - & $4(1.6)$ & - & $3(2.3)$ \\
\hline Total & & 261 & 261 & & 254 & & 257 & & 257 & & 257 \\
\hline \multirow{3}{*}{$\begin{array}{l}\text { Length of } \\
\text { stay in Ha- } \\
\text { Lambani } \\
\text { area in } \\
\text { years }\end{array}$} & $<4$ & $8(3.07)$ & $8(3.07)$ & $P=0.60$ & $8(4.52)$ & $p=0.00$ & $9(3.46)$ & $P=0.92$ & $9(3.5)$ & $P=0.75$ & $13(5)$ \\
\hline & $\geq 5$ & $253(96.93)$ & 253(96.93) & $P=0.60$ & $169(95.5)$ & $P=0.00$ & 251(96.54) & $P=0.92$ & 251(97.67) & $P=0.75$ & $247(95)$ \\
\hline & & 261 & 261 & & 177 & & 260 & & 260 & & 260 \\
\hline
\end{tabular}

Outcome of the focus group discussion.

Overall, the focus group discussion concurred with the questionnaires, however, with a few ideas added.

Knowledge of malaria transmission.

The study participants had heard of malaria and correctly associated it with mosquito bites as the mode of transmission. Others mentioned the close proximity of the village to Kruger National Park as a risk factor of malaria. When asked of their general knowledge or view of malaria, many mentioned that poor practice of malaria prevention measures such as uncleanliness, sleeping with open windows at night, poor disposal of empty cans and diapers, leaving small water dams unattended attracts mosquitoes resulting in malaria; malaria symptoms such as headache, vomiting and body weakness leading to inability to walk; as well as malaria transmission briefly described in the quotes below:

1. "What I know or think about malaria is that it is caused by mosquitoes. Theses mosquitoes come after biting animals that we have in our very own Kruger National Park that we live next to. This is how malaria comes about. When the mosquito bites us as humans whether asleep or awake, it vomits the blood from the animals. That blood from the animals has poison, which is now introduced to the human body. That poison affects your body and results in you not feeling well. You may start feeling cold, get a headache or start vomiting. That's the little that I know."

2. "Once a malaria mosquito bites, it can bite a lot of people in that same household."

3. "Sleeping with open windows at night makes one to be bitten by mosquitoes carrying the malaria parasite".

4. "Also, in this generation, you will find a bucket with diapers in the house, if it doesn't get full or pop from the bottom or something, it will never be removed or emptied! It will only be emptied once the smell becomes unbearable."

The participants mentioned the local health clinic, school, family, Indoor residual Spraying (IRS) team and firsthand experience as the source of malaria information, with more emphasis on the local health clinic. Additionally, in the past, the IRS team would also give medication to those showing malaria symptoms immediately. Participants originally knew malaria as "Mudinyane" which would easily go away once you vomit sometimes, even without taking medication. 
Knowledge of malaria symptoms.

The symptoms of malaria were clearly recognized by focus group participants. Additionally, deafness and sleepiness/exhaustion emerged. Although headache was mentioned in the questionairres, it was however further described in the quote below:

1. "It aches differently from other headaches; you feel it on the forehead and you cannot even walk because of it."

2. "It will ache as pins and needles mainly on the forehead, you will feel like your eyes cannot look up."

3. "On your feet, your knees tremble, you cannot walk long distances without resting and feeling like you are losing your breath."

Knowledge and practice of malaria prevention measures.

Additionally, prevention measures described were using Bunganyunu plant" (Lippia javanica) which is kept in the room for a short while before sleeping. The smell is reported to drive away mosquitoes. Lastly, in addition to burning cow dung, burning tissue or egg holder cardboard of which, the smoke drives away the mosquitoes was also mentioned. Regarding bednet usage, only one participant owned a bednet and used it while the rest of the participants did not use bed-nets due to the reasons expressed in the quote below:

We would like to use the bednets but we don't have them. We cannot afford it, we can't use one for everyone in the house, it's expensive to buy for everyone in the house." If the government can consider us and give us, we would gladly use it.

Most of the study participants correctly reported removal of stagnant water or removal of used cow dung (commonly used for soil-based floor decorations), proper disposal of empty cans and diapers or keeping their compound clean as ways to prevent mosquito breeding with removal of stagnant water or covering water bodies with soil as the most frequently reported measure to prevent mosquito breeding. This is supported by the quote below:

1. "Getting rid of cow dung around the compound, once we do that the mosquito will be ashamed to even come to a clean place."

2. "If there are small water dams around the house, I need to fill them with soil so that water is not stagnant."

In addition, adding bleach (Jik) or salt grains in water drums to keep away mosquitoes emerged as methods to prevent mosquito breeding which were not mentioned from the individual questionnaires.

1. "Another is to use bleach in rain water we collected into water drums, to keep that water clean."

2. "If it rained for example, and I collect water into water drums, I add a granule of salt into the water so that mosquitoes won't enter and breed."

Knowledge of malaria treatment and; treatment seeking behavior.

Focus group participants knew that effective treatments for malaria are available. They further described malaria medication in the following quotations:

1. "Medication for malaria is a malaria drip (intravenous) containing a colorless water like liquid, pills (which are yellow in color of which the dosage is in hours) and malaria injections".

2. "There's another medication, I just do not know what it is called, it is a drip. They inject you; it is effective. They absorb it from a small bottle using an injection and inject it into the drip. You will not even take an hour before you become conscious again. It is very effective."

3. "The yellow pills are bitter, and they (health workers) recommend that we take them with milk, so they can work faster."

These yellow pills are actually artemether-lumefantrine. In addition, participants mentioned that in the past, malaria medication would be distributed as pills (white in color) in the community by malaria IRS workers so that they can use them once malaria symptoms show. These are actually chloroquine or Sulphadoxine-Pyrimethmine (SP) used in the 1990 s for malaria treatment in South Africa) ${ }^{18}$. However, this was later discontinued because girls started using them to terminate pregnancies.

The participants had a positive treatment seeking behavior by stating that they would take their child to the clinic if they had symptoms such as fever. This supported by the quote below:

I would take the child to the clinic to be tested for malaria.

\section{Further comments by participants:}

Study participants had further comments regarding malaria summarized as follows:

1. There should be more awareness programs on malaria in this area, especially in more malarious villages.

2. The government/ department of Health should provide us with a mobile clinic to serve our villages (Tshihothi, Tshamulavhu and Masetoni) so that we do not have to travel such long distances to get assistance.

3. They should provide us with bednets.

4. They should do house to house malaria testing at least once a month.

5. They should provide us with our own ambulance.

\section{Discussion}

Results from surveys on knowledge, attitudes and practices are applicable to design, reformulate or improve malaria control programs, and to identify indicators for a program's effectiveness. This study assessed community knowledge, attitudes and practices surrounding malaria transmission, symptoms,

Page $12 / 16$ 
prevention measures and treatment in Ha-Lambani area of Vhembe District, Limpopo Province, South Africa.

The results of this study showed that the Ha-Lambani community demonstrated adequate knowledge about malaria, transmission, and preventative measures as well as positive treatment seeking behavior as observed in other reports from different parts of the world (South East Iran, Tanzania, North Eastern Ethiopia, Mpumalanga Province, South Africa 19, 20, 21, 22, 23 . All the study participants had heard of malaria, this concurs with other studies done in Tanzania, South Africa, Ethiopia, Swaziland, which accounts for $93-100 \%$ respectively, $15,1923,24$. The most identified source malaria of information by the participants was the local health clinic (85\%). A similar finding was observed in KwaZulu Natal Province, South Africa, Iran, Zambia, Ethiopia and Swaziland, where 49.8-95.5\% of the participants reported health organizations as the main source of malaria information $15,20,22,25,26$. However, a low $29.1 \%$ and $9.6 \%$ accounted for health centers as the source of malaria information in Mpumalanga Province, South Africa and Tanzania, respectively $23,27$.

The majority (95\%) of respondents associated mosquito bites with malaria transmission, which is a common observation in malaria endemic areas. A similar observation ranging between $77 \%$ and $99 \%$ was reported in KwaZulu Natal Province South Africa, Ethiopia, Tanzania, Nigeria and Swaziland $15,19,21,26,28,29$, ${ }^{30}$. These are encouraging results in comparison to $33.2 \%$ observed in Ethiopia ${ }^{25}$. Amongst other villages, Tshihothi village had more participants that had no knowledge on malaria transmission; more awareness on malaria transmission may be needed in this village. Female participants had more knowledge on malaria transmission (77.4\%) compared to males (27.6\%) suggesting a need for more education for the males. Also, no significant difference on malaria transmission knowledge was observed based on level of education.

The knowledge of malaria symptoms is usually high in malaria endemic areas where people are aware of the clinical manifestations of the disease ${ }^{31}$. In the current study, the knowledge about malaria symptoms among participants was relatively poor. Although almost all the participants (99\%), knew at least one common symptom of malaria as seen in Ethiopia (78\%), only $21 \%$ correctly identified the 3 most common symptoms of malaria (headache, chills and fever) ${ }^{1}$, ${ }^{28}$. In contrast to these findings, over $70 \%$ of respondents reported headache, fever or high temperature and chills in Swaziland ${ }^{26}$. The symptoms headache, vomiting and diarrhea were amongst others the most frequently reported symptoms of malaria. This concurs with a study done by Cox in 2018 which reported headache, diarrhea, vomiting and shivering or convulsions as the most frequently reported symptoms of malaria ${ }^{14}$. This is contrary to fever and chills reported by Abate in $2013^{19}$. Participants also mentioned sweating, loss of appetite, fever and chills; and to a lesser extent fatigue, loss of weight, joint pains and others, while a very small portion did not know of any symptoms of malaria. This suggests that the participants lack sufficient knowledge of symptoms specific to malaria. This is an important observation as knowledge of signs and symptoms play a particular role in early diagnosis and treatment of disease

32. More female participants had knowledge on malaria symptoms than males, perhaps male targeted education is needed in the community regarding malaria symptoms.

The participants' knowledge of malaria treatment was extremely low; however, although not the first line drug for malaria, one participant mentioned quinine as medication for malaria treatment. Majority of the participants were quite aware that effective treatment for malaria is available although they did not know specific names of the antimalarials. The majority of respondents simply mentioned pills/tablets (describing the color to be yellow) as medication for the treatment of malaria. This suggests that the community lacks specific details of the medication for malaria treatment that they receive from the local clinic while a small number of the respondents had no knowledge of any form of medication for malaria treatment. Moreover, the participants' knowledge on malaria treatment was significantly higher for females suggesting more education is needed for the males. However, this may be influenced by the small number of male participants in the study.

Knowledge of malaria prevention measures was high (98\%), as observed in Uganda ${ }^{33}$. Wearing long-sleeved clothes was the most prominent malaria prevention measure. This is in contrast with a study done in North Eastern Ethiopia ${ }^{19}$. Historically, African communities have used traditional methods amongst others, in order to keep away mosquitoes. Similarly, in the current study, minority (16.5\%) of the study participants reported the use of unproven prevention measures for malaria control such as burning cow dung, or using plants (such as "Musuzungwane" (Lippia javanica)). Congruent with this study, $22 \%$ of the study participants as reported by Manana; also mentioned these measures ${ }^{15}$. Also, almost half of the study participants mentioned getting rid of stagnant water or covering water bodies as measures to prevent mosquito breeding. This concurs with a study done by Deressa et al. in Ethiopia ${ }^{31}$. Similarly, Aderaw and Gedefaw, reported that $72.6 \%$ of participants mentioned stagnant water as breeding sites for malaria ${ }^{25}$.

A high number of the participants reported to adhere to prevention measures; however, only $3 \%$ of them reported to have slept under a bednet the previous night. Similarly, Manana et al. 2018, found that $2 \%$ of the study participants in KwaZulu Natal Province, South Africa used bednets ${ }^{15}$. In contrast, studies performed in Zimbabwe, Columbia, Ethiopia, Iran and Nigeria found that a higher proportion of the population (17-93\%) reported to practice the use of bednets respectively $34,35,19,36,37$. The poor use of bednets in the current study was due to lack of bednets ownership resulting from low economic status by participants as per the focus group discussion ${ }^{34}$..

Also, this may be due to the fact that South Africa does not provide bednets for its citizens as part of the vector control intervention, however, the Department of Health recommends the use of bednets for personal protection against malaria.

The focus group data concurred with the findings from the individual interviews, however, the following additional information was revealed. Participants originally knew malaria as "Mudinyane" which would easily go away once you vomit; sometimes, even without taking medication. The focus group discussion also revealed other unproven malaria prevention measures which are using plants such as "Bunganyunyu plant" in addition to Musudzungwane plant (Lippia javanica) of which the smell is reported to drive away mosquitoes. Lastly, in addition to burning cow dung, other unproven prevention measures such as burning tissue or egg holder cardboard which also drives away the mosquitoes by its smoke was also mentioned as seen in a study done by Manana in 2018 15. This may be due to perceptions of participants driven by previous experiences. In this context, further research is required to determine the effectiveness of these unproven measures regarding malaria prevention as well as encouragement to use the conventional measures available. Regarding bednet usage, only

Page 13/16 
one participant owned a bednet and used it while the rest of the focus group participants did not practice its usage because of economic barriers. In addition, adding bleach (jik) or salt grains in water drums to keep away mosquitoes also emerged as methods to prevent mosquito breeding.

Although, there should have been a focus on whether or not indoor residual spraying in participants' households have been recently done or not; how often participants get tested for malaria as well as how early the participants seek treatment upon onset of symptoms, this study had notable strengths. These include giving baseline information on malaria perceptions, knowledge, attitudes and practices in the Limpopo Province; as well as adding to malaria awareness in the community by providing informational pamphlets on malaria.

\section{Conclusion And Recommendations}

The study not only demonstrates that participants have appropriate knowledge about malaria but also positive treatment seeking behavior. However, economic barriers are responsible for the inadequate use of bednets as an effective prevention measure. Therefore, distribution of bednets to the community should be considered to improve practice of malaria prevention measures. Also, knowledge of signs and symptoms, appropriate malaria treatment was limited, and initiatives to improve awareness on these topics should be continued. Furthermore, a minority of the community reported the use of unconventional prevention measures. Therefore, further research is necessary (even in other parts of the country endemic for malaria) in order to determine the effectiveness of these unproven prevention measures against malaria as well as encouragement for the use of conventional prevention measures available. The implication may be the same in other areas of the country endemic for malaria, thereby indicating a need to consider these aforementioned aspects in national malaria intervention plans with the overall goal to combat or eliminate malaria.

\section{Abbreviations}

\section{FGD}

Focus Group Discussion

IRS

Indoor Residual Spraying

KAP

Knowledge Attitude and Practices

SP

Supladoxine-Pyrimethmine

\section{Declarations}

\section{Ethics approval and consent to participate}

Ethical approvals for the study were obtained from the Research Ethics and Clinical Trial Committee of the University of Venda (protocol number: SMNS/18/MBY/09/0507) and the Limpopo Provincial Department of Health (Ref: LP_2018 08-020). Permission to conduct the study in the community was obtained from the community leader of Ha-Lambani. Informed consent was obtained from all participants.

\section{Consent for publication}

Not applicable

\section{Availability of data and materials}

All data generated or analyzed during this study are included in this published article.

\section{Competing interests}

The authors declare that they have no competing interests.

\section{Funding}

The research was supported by a Global Infectious Disease Research Training Program (GIDRT) of Fogarty international Center/NIH (D43TW006578), and the University of Venda Higher Degree Committee (SMNS/18/MBY/09/0507). MM benefited from a scholarship by the South African National Research Foundation (GUN108522). The funding bodies had no role in the study and publication process.

\section{Authors' contributions}

MM and RD conceived the study. MM, POB, ETR, RD, JLG, SK and PES contributed to study design. MM led the data collection, drafted the manuscript and analyzed the data. POB, ETR and JLG supervised and reviewed all versions of the draft manuscript. All authors read and approved the final manuscript.

\section{Acknowledgements}

We would like to thank all the study participants, local authorities and the Lambani Clinic for their assistance. 
${ }^{1}$ HIV/AIDS \& Global Health Research Programme, and Department of Microbiology, University of Venda, Thohoyandou, Limpopo Province, South Africa.

${ }^{2}$ Department of Public Health Sciences, University of Virginia, Charlottesville, Virginia, United States of America. ${ }^{3}$ Department of Biology, University of Virginia, Charlottesville, Virginia, United States of America.

${ }^{4}$ Center for Global Health Equity, Department of Infectious Diseases and International Health, University of Virginia, Charlottesville, Virginia, United States of America.

Correspondence: Munzhedzi Mukhethwa (holymunzhedzi@gmail.com)

HIV/AIDS \& Global Health Research Programme, and Department of Microbiology, University of Venda, Thohoyandou, Limpopo Province, South Africa

\section{References}

1. World Health Organization. World malaria report 2019. 105,106,146,184 (2019).

2. Gerritsen, A. A. M., Kruger, P., Van Der Loeff, M. F. S. \& Grobusch, M. P. Malaria incidence in Limpopo Province, South Africa, 1998-2007. Malar. J. 7, (2008).

3. Maharaj, R. et al. Epidemiology of malaria in South Africa: From control to elimination. South African Med. J. 103, 779-783 (2013).

4. Coleman, M. et al. Evaluation of an operational malaria outbreak identification and response system in Mpumalanga Province, South Africa. Malar. J. 7, (2008).

5. Dube, S., Ismail, N. \& Hoosen, A. A. A retrospective review of malaria cases seen in a non-endemic area of South Africa. Travel Med. Infect. Dis. 6, 296-300 (2008).

6. Gerritsen, A. A. M., Kruger, P., van der Loeff, M. F. S. \& Grobusch, M. P. Malaria incidence in Limpopo Province, South Africa, 1998-2007. Malar. J. 7, 162 (2008).

7. Morris, N. et al. Re-defining the extent of malaria transmission in South Africa: implications for chemoprophylaxis. S. Afr. Med. J. 103, 861-864 (2013).

8. Burke, A. et al. A new malaria vector mosquito in South Africa. Sci. Rep. 7, (2017).

9. Craig, M. H., Kleinschmidt, I., Le Sueur, D. \& Sharp, B. L. et al. Exploring 30 years of malaria case data in KwaZulu-Natal, South Africa: part II. The impact of non-climatic factors. Trop. Med. Int. Health 9, 1258-1266 (2004).

10. CDC. Update: South Africa: Limpopo, North West, and Gauteng Provinces. 2020 (2017).

11. Schultz, L. J. et al. A nation-wide malaria knowledge, attitudes and practices survey in Malawi: Objectives and methodology. Trop. Med. Parasitol. 45, 5456 (1994).

12. Govere, J., Durrheim, D., la Grange, K., Mabuza, A. \& Booman, M. Community knowledge and perceptions about malaria and practices influencing malaria control in Mpumalanga Province, South Africa. S. Afr. Med. J. 90, 611-616 (2000).

13. Rodríguez, A. D. et al. Knowledge and beliefs about malaria transmission and practices for vector control in Southern Mexico. Salud Publica Mex. 45, $110-116$ (2003).

14. Cox, S. N. et al. Interactive Malaria Education Intervention and Its Effect on Community Participant Knowledge: The Malaria Awareness Program in Vhembe District, Limpopo, South Africa. Int. Q. Community Health Educ. 38, 147-158 (2018).

15. Manana, P. N., Kuonza, L., Musekiwa, A., Mpangane, H. D. \& Koekemoer, L. L. Knowledge, attitudes and practices on malaria transmission in Mamfene, KwaZulu-Natal Province, South Africa 2015. BMC Public Health 18, 41 (2018).

16. Klassen, W. Introduction: development of the sterile insect technique for African malaria vectors. Malar. J. 4, 1-4 (2009).

17. Moyo, C. S., Francis, J. \& Bessong, P. O. Perceptions of community-based field workers on the effect of a longitudinal biomedical research project on their sustainable livelihoods. BMC Public Health 17, 1-11 (2017).

18. Blumberg, L., Frean, J. \& Moonasar, D. Successfully controlling malaria in South Africa. South African Med. J. 104, 224-227 (2014).

19. Abate, A., Degarege, A. \& Erko, B. Community knowledge, attitude and practice about malaria in a low endemic setting of Shewa Robit Town , northeastern Ethiopia. BMC Public Health 13, 1 (2013).

20. Nejati, J., Hassan, S. \& Saghafipour, M. A. Knowledge, attitude and practice (KAP) on malaria, from high malaria burden rural communities, southeastern Iran. J. Parasit. Dis. 42, 62-67 (2018).

21. Sumari, D., Dillip, A., Ndume, V., Mugasa, J. P. \& Gwakisa, P. S. Knowledge, attitudes and practices on malaria in relation to its transmission among primary school children in Bagamoyo district, Tanzania. MalariaWorld J. 7, (2016).

22. Shimaponda-mataa, N. M., Tembo-mwase, E. \& Gebreslasie, M. Knowledge, attitudes and practices in the control and prevention of malaria in four endemic provinces of Zambia Knowledge, attitudes and practices in the control and prevention of malaria in four endemic provinces of Zambia. South. African J. Infect. Dis. 32, 29-39 (2017).

23. Hlongwana, K. W. et al. Knowledge and practices towards malaria amongst residents of Bushbuckridge, Mpumalanga, South Africa. African J. Prim. Heal. Care Fam. Med. 3, 1-9 (2011).

24. Munisi, D. Z., Nyundo, A. A. \& Mpondo, B. C. Knowledge, attitude and practice towards malaria among symptomatic patients attending Tumbi Referral Hospital: A cross-sectional study. PLoS One 14, 1-12 (2019).

25. Aderaw, Z. \& Gedefaw, M. Journal of Tropical Diseases Knowledge, Attitude and Practice of the Community towards Malaria Prevention and Control Options in Anti-Malaria Association Intervention Zones of Amahara National Regional State, Ethiopia. J. Trop. Dis. 1, 1-7 (2013). 
26. Hlongwana, K. W., Mabaso, M. L. H., Kunene, S., Govender, D. \& Maharaj, R. Community knowledge, attitudes and practices ( KAP ) on malaria in Swaziland: A country earmarked for malaria elimination. Malar. J. 8, 1-8 (2009).

27. Mazigo, H. D. et al. Knowledge, Attitudes, and Practices about Malaria and Its Control in Rural Northwest Tanzania. Malar. Res. Treat. 2010, 1-9 (2010).

28. Alelign, A. \& Petros, B. Knowledge, attitudes and practices of malaria transmission and preventive measures in Woreta town , Northwest Ethiopia. BMC Res. Notes 1-5 (2018). doi:10.1186/s13104-018-3607-z

29. Bamidele, J. O., Ntaji, M. I., Oladele, E. A. \& Bamimore, O. K. Community participation in malaria control in olorunda local government area, Osun State, Southwestern Nigeria. African J. Infect. Dis. 6, 24-28 (2012).

30. Enato, E. F. O., Okhamafe, A. O. \& Okpere, E. E. A survey of knowledge, attitude and practice of malaria management among pregnant women from two health care facilities in Nigeria. Acta Obstet. Gynecol. 86, 33-36 (2007).

31. Deressa, W., Ali, A. \& Enquoselassie, F. ._Deressa et al. (2004).pdf. (2004).

32. Akenji, T. K. N. et al. Evaluating a Malaria Intervention Strategy Using Knowledge, Practices and Coverage Surveys in Rural Bolifamba, Southwest Cameroon. Trans R Soc Trop Med Hyg 99, 6-7 (2005).

33. Musoke, D. et al. Knowledge and practices on malaria prevention in two rural communities in Wakiso District, Uganda. Afr. Health Sci. 15, (2015).

34. Kanyangarara, M. et al. Malaria knowledge and bed net use in three transmission settings in southern Africa. Malar. J. 17, 1-12 (2018).

35. Forero, D. A., Chaparro, P. E., Vallejo, A. F., Benavides, Y. \& Gutiérrez, J. B. Knowledge, attitudes and practices of malaria in Colombia. Malar. J. 13, 1-10 (2014).

36. Fekri, S. et al. Malaria Situation in an Endemic Area, Southeastern Iran. J. Arthropod Borne Dis. 8, 82-90 (2014).

37. Adedotun, A. A., Morenikeji, O. A. \& Odaibo, A. B. Knowledge, attitudes and practices about malaria in an urban community in south-western Nigeria. J. Vector Borne Dis. 47(3):, 155-159 (2010). 